\title{
Resumo do Mapeamento Sistemático sobre o método Problem Based Learning
}

\author{
Ivan dos Santos Peixoto ${ }^{1}$; José Amancio Macedo dos Santos ${ }^{2}$ \\ 1. Bolsista PIBIC/CNPq, Graduando em Engenharia da Computação, Universidade Estadual de Feira de Santana, e- \\ mail: snavisp@gmail.com \\ 2. Orientador, Departamento de Tecnologia, Universidade Estadual de Feira de Santana, e-mail: \\ zeamancio@gmail.com
}

PALAVRAS-CHAVE: Mapeamento sistemático; PBL; Estudos secundários.

\section{INTRODUÇÃO}

A metodologia de Aprendizagem Baseada em Problemas (PBL) é adotada no curso de Engenharia de Computação da UEFS desde seu surgimento em 2003, representando um importante diferencial na formação do aluno $[1,2]$. O método PBL propõe que o aluno aprenda o conteúdo proposto de forma diferente, simulando um ambiente de criação e discussão de projetos, como nas empresas.

Um método desta natureza requer constante aprimoramento dos atores envolvidos em sua aplicação. Vários aspectos envolvem a aplicação do método de forma adequada. Um deles é a uniformidade de aplicação do PBL no curso. Outra se refere ao impacto causado na aprendizagem do estudante. Há também a necessidade de os tutores seguirem um modelo adequado e uniforme de avaliação e atuação com suas turmas.

Uma das dificuldades em tratar estas questões é que a maior parte dos professores envolvidos no PBL do curso de Engenharia da Computação não possui formação que enfoque métodos pedagógicos de ensino. A maior parte dos professores teve contato com o método quando ingressaram na UEFS e no curso de Engenharia de Computação. Este contato tipicamente ocorreu a partir de oficinas e recomendações de leituras realizadas pelos próprios professores do curso. Uma das dificuldades que os professores enfrentam, entretanto, é que as atividades de pesquisa, ensino e extensão dificultam a disponibilização de tempo para o aprimoramento constante sobre o método PBL. Atualmente há um extenso conjunto de estudos sendo realizados sobre o método PBL $[3,4,5,6]$. O problema é tornar este conhecimento acessível e útil para a aplicação do PBL no curso de Engenharia da Computação.

\section{MATERIAL E MÉTODOS OU METODOLOGIA (ou equivalente)}

Neste plano utilizamos o método de estudo denominado Mapeamento Sistemático (MS). O mapeamento sistemático é um método de estudo secundário que visa proporcionar uma visão mais ampla de um tópico de pesquisa, verificando se há e a quantidade de evidências de pesquisa do tema proposto.

As atividades desenvolvidas durante a pesquisa foram:

1 - Estudo e compreensão dos métodos de pesquisa (MS)

2 - Definição do protocolo do MS

Definição de fontes de pesquisa -

Definição da string de busca

Definição dos critérios de inclusão/exclusão

3 - Realização do MS

- Execução do protocolo

4 - Analise dos dados levantados

5 - Apresentação dos resultados (relatórios necessários) 
Os dados das pesquisas a serem realizadas durante a execução do projeto foram extraídos de leituras a partir da aplicação do protocolo do MS. Buscamos estudos que expõem os benefícios que o método lhes proporcionou, bem como as dificuldades enfrentadas ou possíveis pontos em que a forma de aprendizagem não teve bom êxito, bem como a forma como o método é aplicado.

\section{RESULTADOS E/OU DISCUSSÃO (ou Análise e discussão dos resultados)}

- Ano - demonstra que o número de publicações se mantém estável entre 2 e 5 artigos, mas há picos nos anos de 2009/2010 e 2014/2015 quando o número de artigos ficou entre 8 e 12.

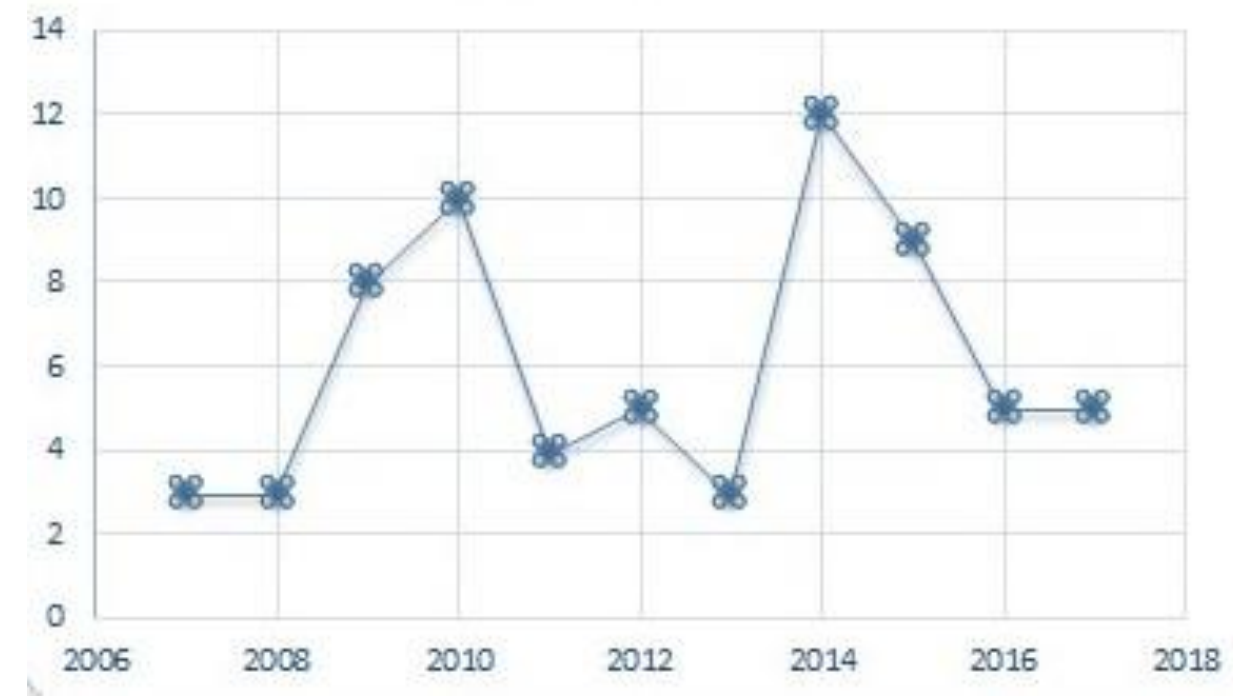

Figura 1: Gráfico de com o esquema de publicações estudadas no decorrer dos anos de 2007 a 2017.

- Instituições - dado o agrupamento de autores da mesma instituição nos artigos, desconsideramos as instituições e consideramos os países onde os estudos foram realizados. Identificamos 23 países diferentes. Em 15 artigos os países não foram mencionados. Os números destacam Brasil e Espanha, com 8 e 11 artigos, respectivamente. Para a maioria dos países identificados poucos artigos são apresentados, o que reflete também a pouca concentração de artigos por autores.

- Disciplinas - Também no caso das disciplinas, a variação é grande. Descobrimos 77 disciplinas diferentes. Engenharia de Software (ES) é a disciplina encontrada em mais artigos (12). No gráfico, além de ser destacada as disciplinas ligadas à Engenharia de Software (21), e que algumas áreas são pouco abordadas (como é o caso de Questões Sociais, Algoritmos e outros), não é possível destacar nenhum padrão. Uma conjectura é que as disciplinas da ES permitem soluções mais abertas, pois podem envolver diferentes tipos de métodos e processos. Entretanto, não podemos dizer se isso ocorre porque é mais "fácil" preparar problemas para ES ou se é porque a natureza da ES se alinha mais com os a estruturação do PBL. Estudaremos este fenômeno no futuro. 


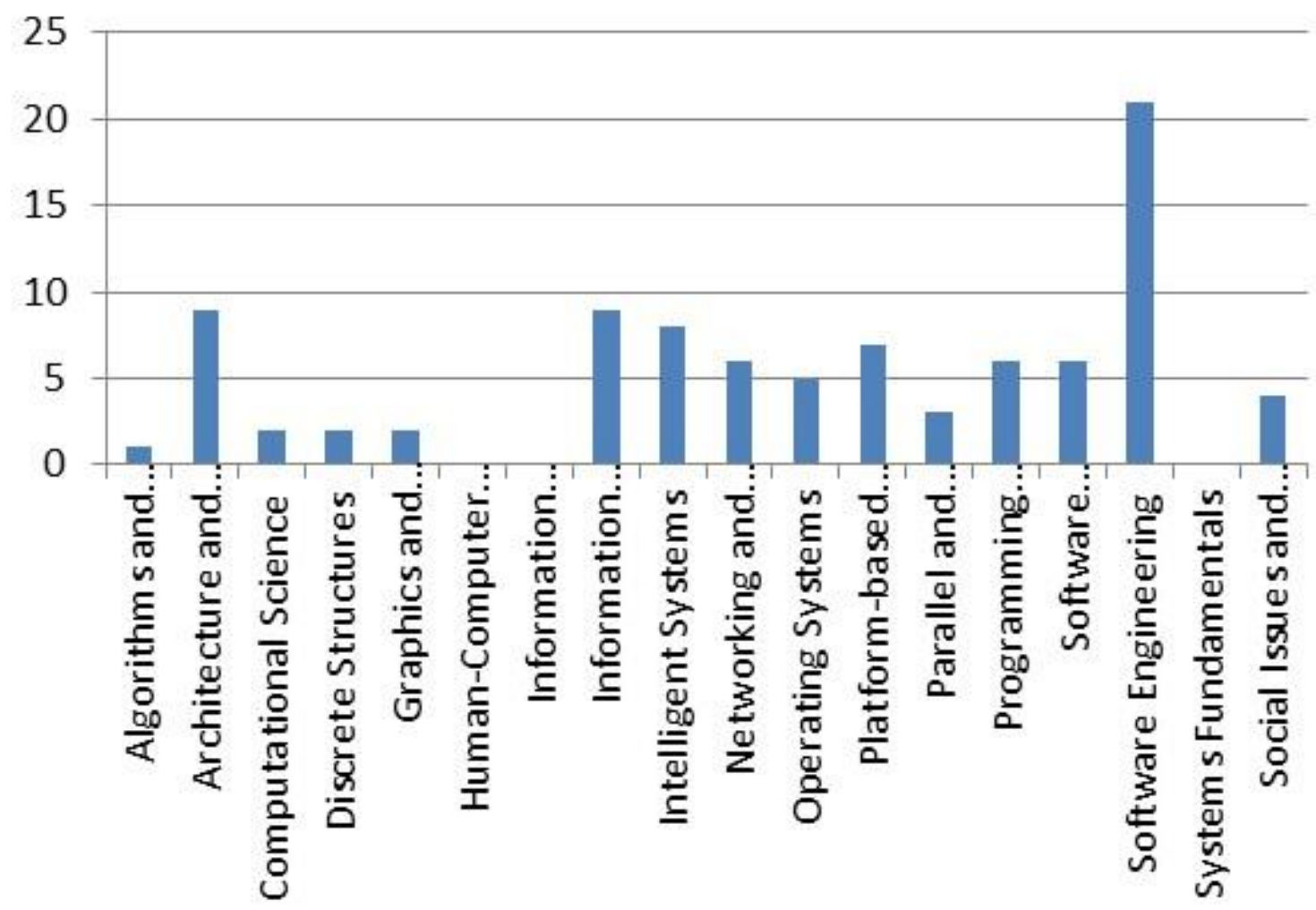

Figura 2: Gráfico com a quantidade de ocorrências em disciplinas de Computação.

- Tipo - A maioria da forma de aplicação do PBL é como "Segmento" (são 56 em 68 $87.5 \%$ dos "casos encontrados" - "casos encontrados" = 68 - 4 casos em que não identificamos a forma de aplicação).

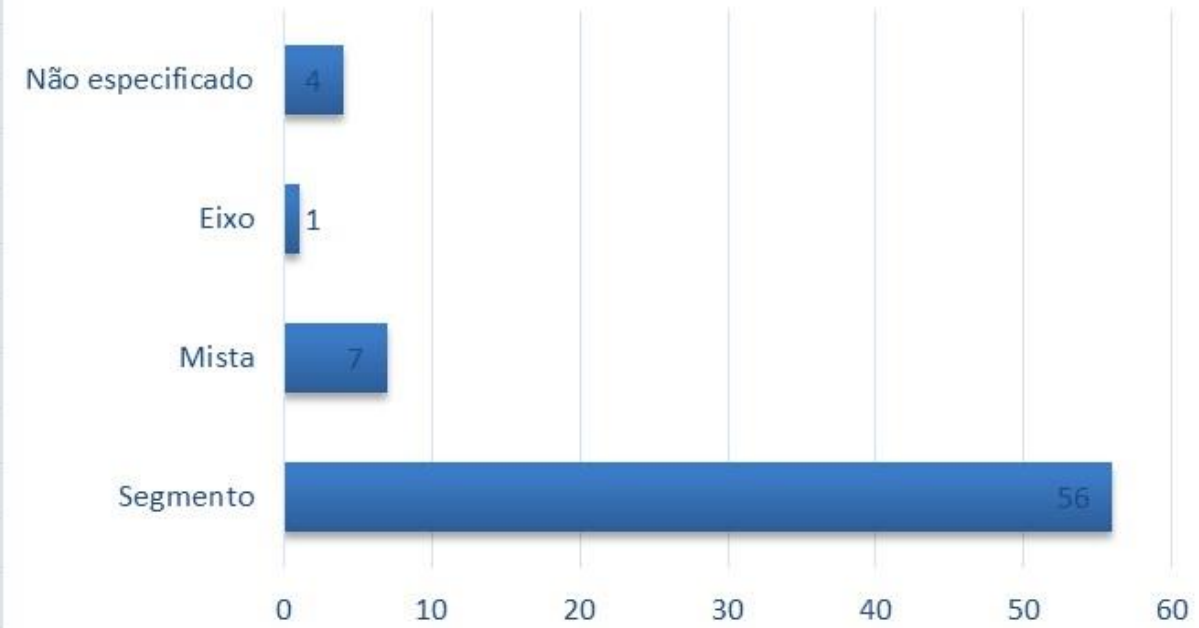

Figura 3: Gráfico da distribuição dos relatos observados de acordo com a classificação de aplicação do PBL. 


\section{CONSIDERAÇÕES FINAIS (ou Conclusão)}

Com base nos dados extraídos, que mostram que a metodologia, bem como sua aplicação, não é profundamente estudada e discutida, não conseguimos argumentos suficientes para afirmar se o PBL é realmente um diferencial essencial para os cursos de Computação.

\section{REFERÊNCIAS}

1 - SANTOS, D. M. B. ; PINTO, G. R. P. R. ; SENA, C. P. P. ; BERTONI, F. C. ; BITTENCOURT, R. A. . Aplicação do Método de Aprendizagem Baseada em Problemas no Curso de Engenharia de Computação da Universidade Estadual de Feira de Santana. In: COBENGE 2007 - XXXV Congresso Brasileiro de Educação em Engenharia, 2007, Curitiba. Anais do XXXV Congresso Brasileiro de Educação em Engenharia, 2007. p. 2A07-01-2A07-14

2 - SANTOS, J. A. M. ; ANGELO, M. F. ; LOULA, A. . Utilização do método PBL em um Estudo Integrado de Programação. In: XXXVI Congresso Brasileiro de Educação em Engenharia, 2008, São Paulo. Anais do XXXVI Congresso Brasileiro de Educação em Engenharia, 2008.

3 - A. M. C. A. Oliveira, S. C. dos Santos and V. C. Garcia, "PBL in teaching computing: An overview of the last 15 years," Frontiers in Education Conference, 2013 IEEE, Oklahoma City, OK, 2013, pp. 267-272. doi: 10.1109/FIE.2013.6684830

4 - Michael J. O'Grady. 2012. Practical Problem-Based Learning in Computing Education. Trans. Comput. Educ. 12, 3, Article 10 (July 2012), 16 pages.

5- Ana Paula L. Ambrósio and Fábio M. Costa. 2010. Evaluating the impact of PBL and tablet PCs in an algorithms and computer programming course. In Proceedings of the 41 st ACM technical symposium on Computer science education (SIGCSE '10). ACM, New York, NY, USA, 495-499

6- Nuutila, E., T” orm“" a, S., Kinnunen, P, and Malmi, L. 2008. Learning programming with

the PBL method - Experiences on PBL Cases and Tutoring. In Reflections on the Teaching of Programming, Lecture Notes In Computer Science, 4821.47-67.

O'Kelly,

7- O'Grady, Michael J. (2012) Practical Problem-Based Learning in Computing Education, ACM

8- KITCHENHAM, B.; CHARTERS, S. Guildelines for performing systematic literature reviews in software engineering. Technical Report EBSE-2007-01, School of Computer Science and Mathematics, Keele University, 2007. 